\title{
Parasitism of Dinophysis norvegica by Amoebophrya sp. in the Baltic Sea
}

\author{
Paulo S. Salomon*, Sven Janson, Edna Granéli \\ Department of Biology and Environmental Science, University of Kalmar, Landgången 3, 39182 Kalmar, Sweden
}

\begin{abstract}
The temporal and vertical distribution of the infection of the dinoflagellate Dinophysis norvegica by the endoparasite Amoebophrya sp. was investigated at a fixed sampling location in the Baltic Sea during 2000 and 2001. Infected hosts were detected by epifluorescence microscopy after DAPI staining. The maximum depth-averaged parasite prevalence was $2.3 \%$ in July 2000 and $1.8 \%$ in August 2001. The percentage of infected hosts was usually higher close to the thermocline than at the surface. The highest parasite prevalence at a specific depth (4.8\%) was found at $20 \mathrm{~m}$ in August 2001. No correlation was observed between parasite prevalence and host abundance or dissolved nutrient ( $\mathrm{N}$ and $\mathrm{P}$ ) concentrations, neither for depth-averaged nor discrete depth measurements. However, temperature seemed to be an important factor influencing infection of $D$. norvegica by Amoebophrya sp., with infected host cells observed only above $12^{\circ} \mathrm{C}$. Amoebophrya sp. was only sporadically observed inside other dinoflagellate species, indicating specificity towards $D$. norvegica. The seasonal pattern of infection suggests the existence of a dormancy stage of the parasite dinospores. The low prevalence observed during this study indicates that parasitism by Amoebophrya sp. is not a relevant loss factor for D. norvegica in the Baltic Sea.
\end{abstract}

KEY WORDS: Phytoplankton · Interspecific interactions · Parasitism · Dinoflagellates · Amoebophrya · Dinophysis norvegica $\cdot$ Baltic Sea

\section{INTRODUCTION}

Several dinoflagellate species have been recognized as parasites infecting a great variety of taxa, from phytoplankton to crustaceans and fishes (Drebes 1984, Cachon \& Cachon 1987, Coats 1999). Members of the genus Amoebophrya are able to infect other marine dinoflagellates (Cachon \& Cachon 1969, Coats \& Bockstahler 1994, Coats et al. 1996) including toxinproducing and red-tide forming species (Taylor 1968, Nishitani et al. 1985, Coats et al. 1996). Infection of dinoflagellates by Amoebophrya sp. is intracellular (sometimes intranuclear) and the process is lethal to the host cell (Cachon \& Cachon 1987). Thus, these parasites may represent a significant loss factor for dinoflagellate populations in nature, and are potential biological control organisms against harmful species (Taylor 1968). The infection of Amoebophrya sp. is mediated by free-swimming dinospores that enter the host cell and develop into a trophont stage that consists of a single multinucleated, multiflagellated cell. When mature, the trophont contains 100s of nuclei, and its many flagella are arranged in an internal cavity, the mastigocoel, that results from its growth inside the host (Cachon \& Cachon 1969, 1987, Fritz \& Nass 1992, Maranda 2001). At the end of the intracellular phase, the parasite trophont goes through a remarkable morphological transformation, evaginating through the aperture of the mastigocoel and leaving the host to become a vermiform that eventually differentiates and breaks apart releasing the new infective dinospores (Cachon \& Cachon 1987). While a relatively large amount of information has been accumulated on the intracellular phase of Amoebophrya sp. infecting dinoflagellates, most aspects regarding the biology and fate of the free-living dinospores remain unexplored. However, ingestion of Amoebophrya dinospores by tintinnids and rotifers has been described in nature (Maranda 2001), and grazing 
on the parasite dinospores by ciliates influences the infection process of the host Akashiwo sanguinea under culture and in the field (Johansson \& Coats 2002). Temperature and nutrient conditions also influence the infection process by Amoebophrya sp. (Coats \& Bockstahler 1994, Yih \& Coats 2000).

Occurrence of Amoebophrya sp. in dinoflagellate cells is a widespread phenomenon, being reported in coastal waters from different parts of the globe (Taylor 1968, Cachon \& Cachon 1987, Fritz \& Nass 1992, Coats et al. 1996, Janson et al. 2000, Maranda 2001). The percentage of cells infected by Amoebophrya sp. reported for host dinoflagellate populations in nature varies over 2 orders of magnitude (Coats 1999), with levels as high as $80 \%$ observed during localized epidemics in the photosynthetic dinoflagellate Gyrodinium uncatenum (Coats et al. 1996). In the Baltic Sea, Amoebophrya sp. has been previously reported to infect the dinoflagellate Dinophysis norvegica (Janson et al. 2000), with prevalence ranging from 0.2 to $6 \%$ during summer months (Gisselson et al. 2002). However, there is no information regarding the seasonal pattern of infection of $D$. norvegica by the parasite in the Baltic Sea. $D$. norvegica is one of the most abundant dinoflagellates during summer in the open Baltic Sea, and subsurface blooms of this species are recurrent phenomena in the area (Carpenter et al. 1995, Gisselson et al. 2002).

Morphological aspects of Amoebophrya sp. development inside Dinophysis norvegica have been described for this host-parasite system in Mahone Bay, Nova Scotia, Canada (Fritz \& Nass 1992). However, recent investigations have shown that morphologically similar Amoebophrya sp. infecting dinoflagellates are genetically highly dissimilar, probably representing different species (Janson et al. 2000, Gunderson et al. 2002). Furthermore, the emergence of Amoebophrya sp. from its host $D$. norvegica has not been described in detail.

Our goals in the present work were to investigate: (1) the temporal and vertical distribution patterns of infection by Amoebophrya sp. in Dinophysis norvegica and other potential dinoflagellate hosts at a fixed sampling location in the Baltic Sea; and (2) the relationship between parasite prevalence and in situ physicochemical parameters. Additionally, a morphological description of infected cells and the parasite's emergence from $D$. norvegica based on light and epifluorescence microscopy observations of live and fixed material is presented.

\section{MATERIALS AND METHODS}

Sampling. Samples were collected at a fixed station in the open Baltic Sea $\left(56^{\circ} 36.5^{\prime} \mathrm{N}, 16^{\circ} 53.5^{\prime} \mathrm{E}\right)$ at approximately monthly intervals from April to October
2000 and 2001. During 2000, samples were taken only to estimate the depth-averaged percentage of Dinophysis norvegica cells infected by Amoebophrya sp. In a more detailed study during 2001, samples were also taken for quantification of infected host cells, host densities and inorganic nutrient ( $\mathrm{N}$ and $\mathrm{P}$ ) concentrations as described below. On all sampling occasions in 2000 and 2001, in situ temperature and salinity were measured with a probe thermo-conductivimeter (WTW model LF196).

Cell counting and nutrient analysis. During 2001, samples were collected at 1 to $3 \mathrm{~m}$ intervals $(5 \mathrm{~m}$ intervals in April) between the surface and $20 \mathrm{~m}$ depth (25 m depth in July) with a 31 Niskin bottle for quantification of Dinophysis norvegica and other dinoflagellate cells and nutrient concentrations. Aliquots of 21 from each depth were concentrated to $20 \mathrm{ml}$ with a $5 \mu \mathrm{m}$ mesh-size plankton net and preserved in $2.5 \%$ glutaraldehyde for further cell counting in settling chambers (Utermöhl 1958) in an inverted microscope (Nikon Diaphot-TMD) at $200 \times$ magnification. Inorganic nitrogen $\left(\mathrm{NO}_{3}, \mathrm{NO}_{2}, \mathrm{NH}_{3}\right)$ and phosphorus $\left(\mathrm{PO}_{4}\right)$ concentrations were determined from samples taken every $5 \mathrm{~m}$ (Valderama 1995).

Parasite prevalence. To estimate parasite prevalence (= percentage of infected cells) in Dinophysis norvegica and other potential host dinoflagellate species, samples were collected in 2 ways. To estimate the depth-averaged infection level for the water column, vertical net tows from $20 \mathrm{~m}$ depth to the surface were taken with a $20 \mu \mathrm{m}$ mesh-size plankton net on all sampling occasions in 2000 and 2001. Parasite prevalence at discrete depths was estimated only during the 2001 survey. To obtain enough host cells for the analysis, volumes of approximately 3001 were sampled at $5 \mathrm{~m}$ intervals between the surface and $20 \mathrm{~m}$ depth $(25 \mathrm{~m}$ in July) using a water pump. Phytoplankton cells in the pumped water were concentrated with a $20 \mu \mathrm{m}$ meshsize plankton net. Phytoplankton cells from both the vertical net tows and discrete depths were further concentrated between 20 and $70 \mu \mathrm{m}$. The cell concentrates were transferred to $15 \mathrm{ml}$ polycarbonate tubes, fixed with $10 \mathrm{ml}$ cold phosphate buffered saline (PBS) (10 $\mathrm{mM} \mathrm{Na}_{2} \mathrm{HPO}_{4}, 10 \mathrm{mM} \mathrm{NaH}_{2} \mathrm{PO}_{4}, 100 \mathrm{mM} \mathrm{NaCl}, \mathrm{pH}$ 6.8) containing $5 \%(\mathrm{w} / \mathrm{v})$ paraformaldehyde for $30 \mathrm{~min}$, centrifuged $(1 \mathrm{~min}$ at $500 \times \mathrm{g})$, and subsequently washed once with $5 \mathrm{ml}$ cold PBS and twice with $5 \mathrm{ml}$ cold $70 \%(\mathrm{v} / \mathrm{v})$ ethanol. Cells were resuspended in $2 \mathrm{ml} 70 \%$ ethanol and stored at $-20^{\circ} \mathrm{C}$. To estimate the percentage of infection by Amoebophrya sp., small volumes (50 to $100 \mu l)$ of the cell suspensions were centrifuged $(1 \mathrm{~min}$ at $500 \times g)$, resuspended in $1 \mathrm{ml}$ PBS containing $0.1 \mathrm{mg} \mathrm{ml}^{-1}$ RNase, and kept in a water bath at $37^{\circ} \mathrm{C}$ for $3 \mathrm{~h}$. After centrifugation, cells were stained with $1 \mathrm{ml}^{2} \mu \mathrm{g} \mathrm{ml}^{-1}$ DAPI for $1 \mathrm{~h}$, centrifuged (1 min at 
$500 \times g$ ), rinsed with $0.5 \mathrm{ml} \mathrm{PBS}$, and the volume reduced to between 30 and $50 \mu$ l. The cell suspensions were subsequently mounted on microscope slides and observed in an epifluorescence microscope (Olympus BX 50) equipped with a UV filter (Olympus U-MNU: $\lambda_{\text {ex }} 360$ to $370 \mathrm{~nm}, \lambda_{\text {em }}>420 \mathrm{~nm}$ ) at $400 \times$ magnification. A total of 2000 D. norvegica cells were analyzed per sample for the presence of Amoebophrya sp. In selected samples, other dinoflagellate species were also analyzed for infection (between 500 and 2000 cells depending on their abundance). For the sampling occasions during 2001, when parasite prevalence in D. norvegica observed from the vertical net tows were $>0.1 \%$, samples taken at different depths in the water column were also analyzed. The size of the parasite trophont inside $D$. norvegica from samples collected at different depths in August and September 2001 was estimated using scaled circles printed on the microscope's ocular. A total of 30 or 50 trophonts were analyzed per sample, depending on the abundance of infected cells and material available, and separated into 5 size classes according to the scales in the microscope. Fluorescence of live cells was observed with a blue filter (Olympus U-MNB: $\lambda_{\text {ex }} 470$ to $490 \mathrm{~nm}, \lambda_{\mathrm{em}}>$ $550 \mathrm{~nm}$ ). Pictures were taken with an Olympus DP50 digital camera coupled to the microscope at $400 \times$ magnification in automatic exposure mode.

Parasite emergence from the host. The emergence of the parasite Amoebophrya sp. from Dinophysis norvegica was observed using live material collected in August 2001. Samples were placed in an inverted microscope equipped with epifluorescence (Nikon Diaphot-TMD), and D. norvegica cells containing a mature Amoebophrya sp. trophont were identified by the characteristic green autofluorescence of the parasite elicited under blue light. Several emergence events were recorded using an Ikegami ICD 800P camera connected to a VHS video cassette recorder. The movies were then digitalized and used to generate some of the pictures presented in this paper.

Calculation of averaged cell density and parasite prevalence. Depth-averaged cell concentration and parasite prevalence during 2001 were estimated by weighted mean, allowing for the variable depth intervals from which cell concentration and percentage of infected host cells were measured.

\section{RESULTS}

\section{Hydrology and dissolved nutrients}

Surface water temperature ranged from 3.2 to $17.1^{\circ} \mathrm{C}$ with maxima in August during both 2000 and 2001 (Fig. 1a). Salinity was typically around 6\%o with minimal seasonal and depth variations. Depth-averaged concentrations of inorganic nitrogen $\left(\mathrm{NO}_{3}+\mathrm{NO}_{2}+\mathrm{NH}_{3}\right)$ for the upper $20 \mathrm{~m}$ water column were around $0.2 \mu \mathrm{M}$ from April to August 2001 and increased to $0.8 \mu \mathrm{M}$ in October (Fig. 1b). Inorganic phosphorus concentration showed an opposite trend, decreasing from levels around $0.3 \mu \mathrm{M}$ in April and June to $0.05 \mu \mathrm{M}$ in September and October (Fig. 1c). As a consequence of the high nitrogen and low phosphorus levels observed towards the autumn, the $\mathrm{N}: \mathrm{P}$ values that were below 5 until June increased to approximately 8 in August and September, and reached the highest value of 16.8 in October (Fig. 1d). Both inorganic nitrogen and phosphorus concentrations were low at the surface and increased with depth (data not shown). The water column during the study period varied from well mixed in April and gradually changed to a stratified situation with a marked thermocline in July onward. The depth of the upper mixed layer ranged between 12 and $22 \mathrm{~m}$ (Fig. 2).
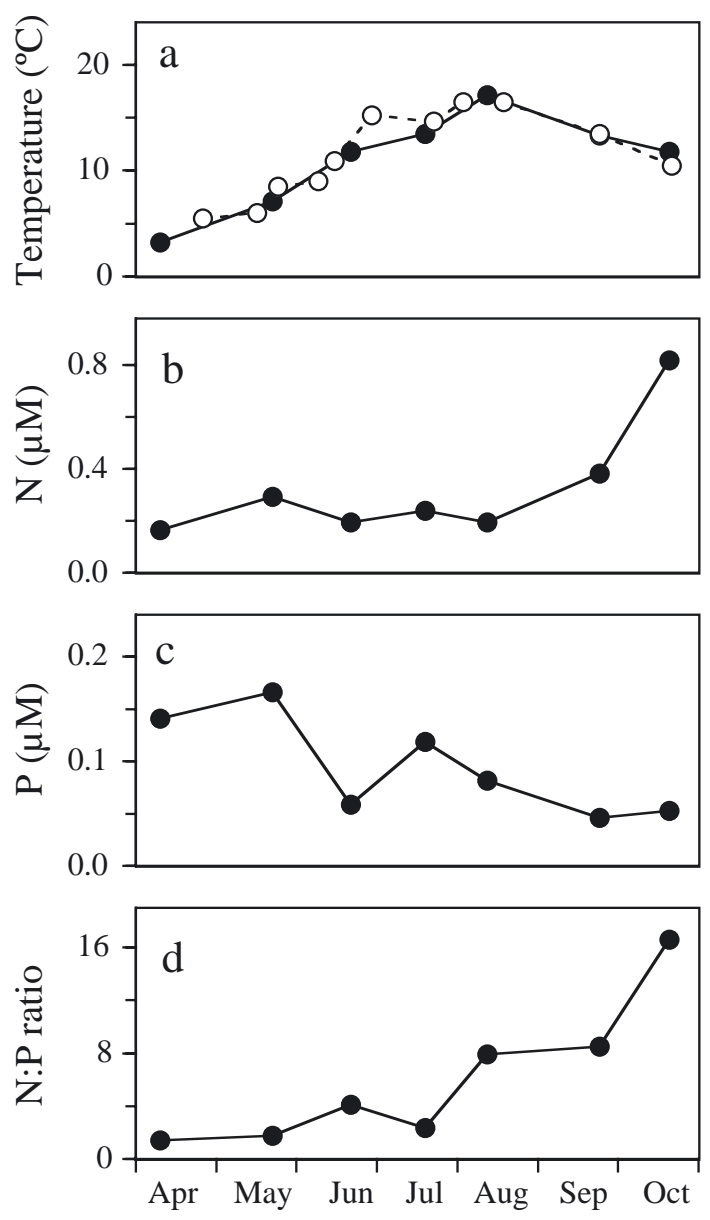

Fig. 1. Seasonal variation of (a) surface water temperature, (b) inorganic nitrogen $\left(\mathrm{NO}_{3}+\mathrm{NO}_{2}+\mathrm{NH}_{3}\right)$, (c) inorganic phosphorus $\left(\mathrm{PO}_{4}\right)$ and $(\mathrm{d})$ the $\mathrm{N}: \mathrm{P}$ ratio at a fixed station in the Baltic Sea during 2001. Surface water temperature during 2000 is also shown in (a) (O) 


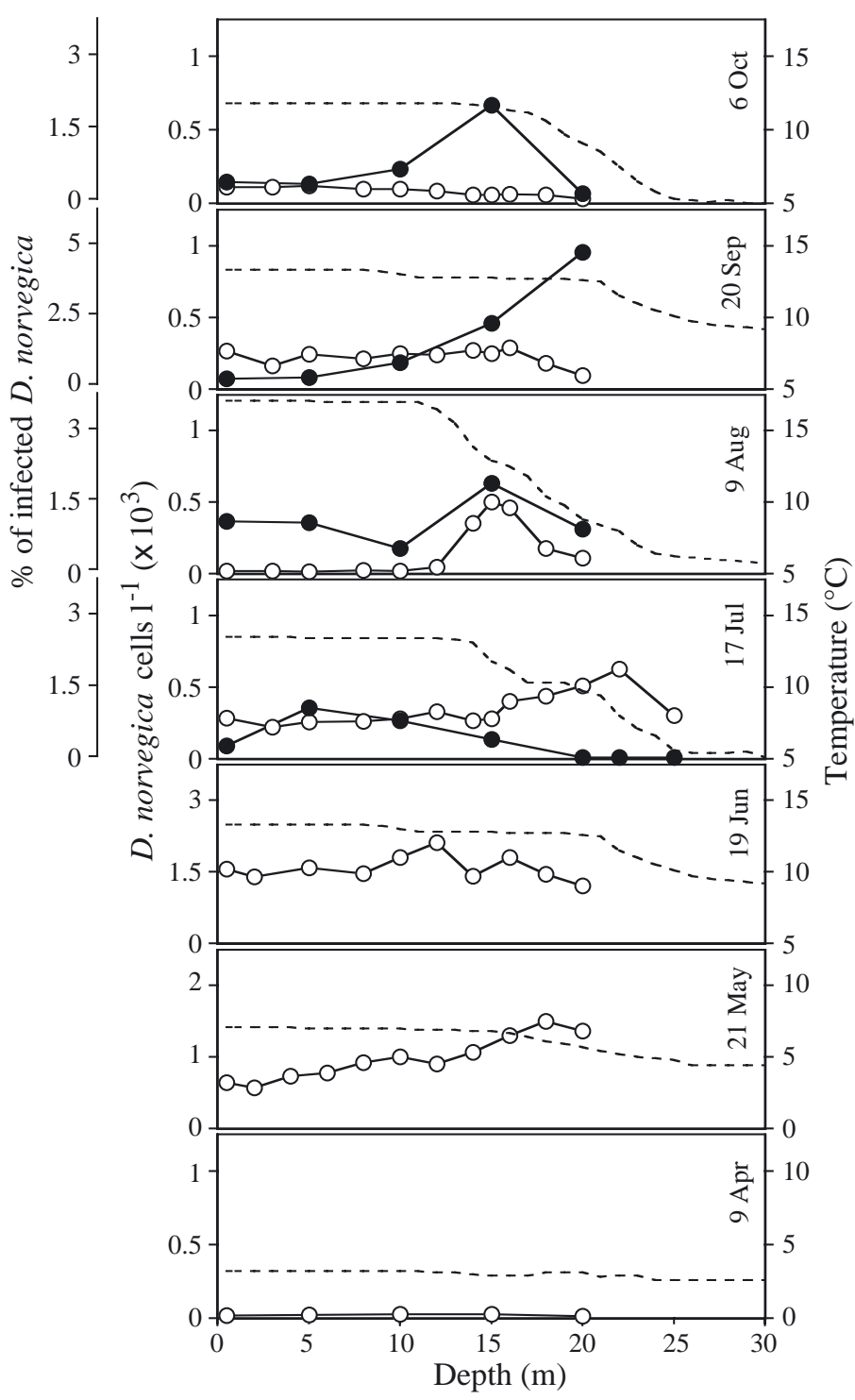

Fig. 2. Vertical profiles of Dinophysis norvegica cell densities (O), \% of D. norvegica infected by Amoebophrya sp. (•) and temperature (- - -) for the sampling occasions in the Baltic Sea between April and October 2001. Note that the scale representing \% of infection on 20 September is different from the others

\section{Host densities}

During the investigation conducted in 2001, 3 species of Dinophysis (D. norvegica, D. acuminata and D. rotundata) were present at detectable amounts. $D$. norvegica was the most abundant, except in April when D. acuminata was dominant. Depth-averaged D. norvegica density increased from 22 cells $\mathrm{l}^{-1}$ in April to a maximum of 1590 cells $l^{-1}$ in June, with a further decrease to 307 cells $~^{-1}$ in July and lower levels from August to October (Fig. 3). D. acuminata cells were present on all but 1 sampling occasion (October), with a seasonal trend similar to D. norvegica, although at lower levels, with a maximum of 304 cells ${ }^{-1}$ in June and less than 10 cells $\mathrm{l}^{-1}$ in July and August (Fig. 3). D. rotundata was only found at detectable concentrations in September and October, at levels around 10 cells $\mathbf{~}^{-1}$. Furthermore, high numbers of the chain-forming, photosynthetic dinoflagellate Peridiniella catenata were observed in April exceeding 6200 cells $1^{-1}$ close to the surface and averaging 4900 cells $\mathrm{l}^{-1}$ for the $20 \mathrm{~m}$ water column.

The depth profiles of Dinophysis norvegica densities showed different patterns on the 7 sampling occasions in 2001 (Fig. 2). On most occasions, the cells were evenly distributed through the water column, with no pronounced high cell densities peaks. One exception was in August, when a layer of higher D. norvegica density was observed around $15 \mathrm{~m}$ depth in the middle of the thermocline.

\section{Parasite prevalence}

Dinophysis norvegica was by far the most infected dinoflagellate species observed during this study. Noninfected $D$. norvegica stained with DAPI showed an elongated, compact nucleus measuring around $25 \mu \mathrm{m}$ and typically located in the central region of the cell (Fig. 4d). Infected cells were recognized by the many nuclei of the parasite's trophont inside the host (Fig. 4f,g). Infected D. norvegica cells lacked a nucleus. Curiously, some host cells within the infected population displayed an abnormal, hollow nucleus (compare Fig. 4d and e), which may represent an early stage of infection by the parasite. Since we were not sure whether this was the case, such cells were scored as non-infected. Only rarely were $D$. norvegica cells observed to harbor 2 trophonts. Apart from D. nor-

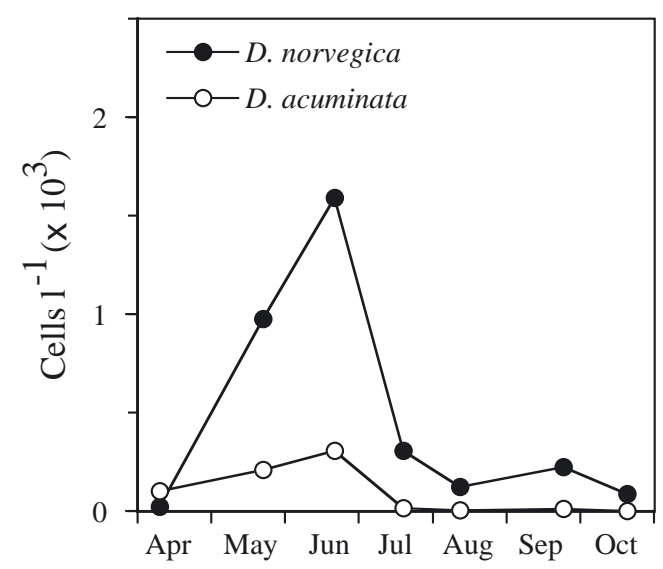

Fig. 3. Depth-averaged cell densities of Dinophysis norvegica and D. acuminata during 2001 
vegica, the parasite trophont was only sporadically observed inside other host species. A few infected $D$. acuminata (Fig. 4h,i) and an unidentified peridinoid dinoflagellate (Fig. 4j,k) were observed to contain the multinucleate Amoebophrya sp. trophont pattern. D. rotundata was present in September and October
2001, but without detectable infection. Similarly, no infection was observed in Peridiniella catenata, although it had high cell numbers in April 2001.

The depth-averaged parasite prevalence in Dinophysis norvegica estimated from the vertical net tows showed a similar pattern during the 2 years monitored
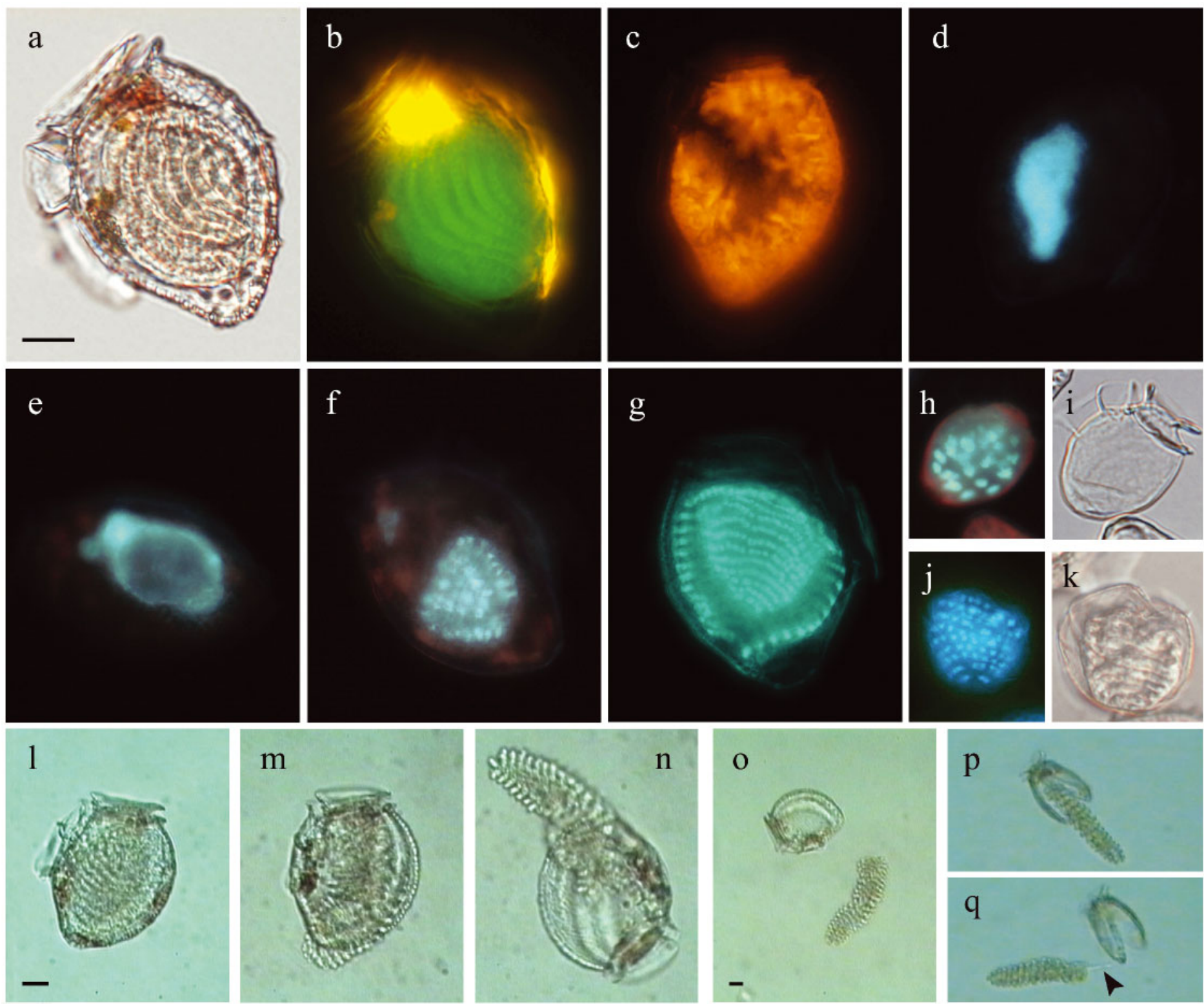

Fig. 4. Bright field and epifluorescence micrographs of Dinophysis norvegica and other dinoflagellate species from the Baltic Sea. (a,b) Live $D$. norvegica cell harboring an Amoebophrya sp. trophont observed under bright field and epifluorescence (blue-light excitation), respectively. (c) Live, uninfected $D$. norvegica cell observed under epifluorescence. (d) Non-infected, DAPI-stained $D$. norvegica cell observed under UV-light excitation. (e) DAPI-stained D. norvegica showing an abnormal nucleus with a hollow space. $(\mathrm{f}, \mathrm{g})$ Infected, DAPI-stained $D$. norvegica cells showing a small and a mature Amoebophrya sp. trophont, respectively; in both cells, the trophont mastigocoel appears as the smile-shaped, less stained region. $(\mathrm{h}, \mathrm{i})$ Epifluorescence and bright field micrographs of an infected D. acuminata cell. $(\mathrm{j}, \mathrm{k})$ A peridinoid dinoflagellate harboring a mature Amoebophrya sp. trophont. $(1,0)$ Snapshots of the emergence process of Amoebophrya sp. from a D. norvegica cell; the time span between (l) and (o) is approximately 2 min. $(\mathrm{p}, \mathrm{q})$ An Amoebophrya sp. vermiform that has emerged from the posterior region of the host; in this particular case, the vermiform stayed attached to the host for several minutes by a thin, mucous filament (arrowhead). Scale bars $=10 \mu \mathrm{m}$ : scale bar in (a) applies also for (b) to (k); scale bar in (l) applies also to (m) and (n); scale bar in (o) applies also to (p) and (q). Original magnification: (a to n) 400 $\times$; (o to q) $200 \times$ 


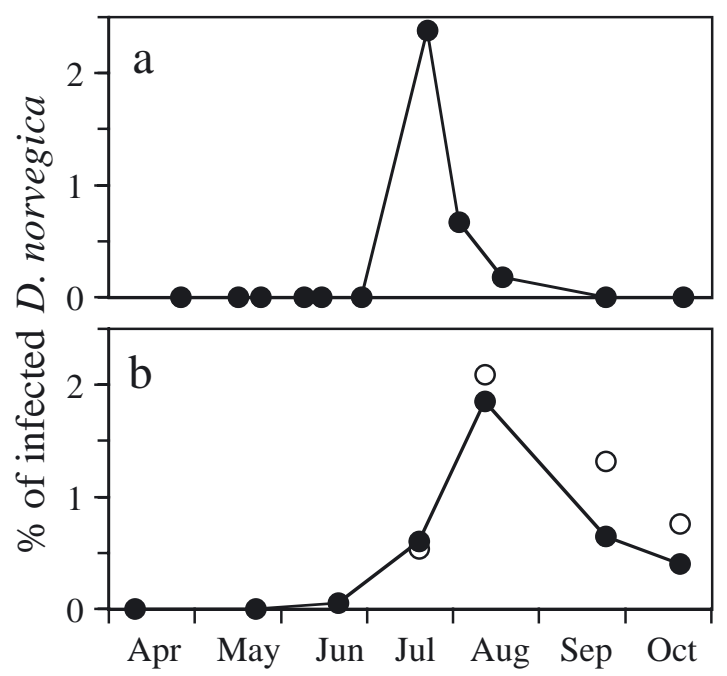

Fig. 5. Depth-averaged percentage of Dinophysis norvegica cells infected by Amoebophrya sp. estimated from vertical net tows (20 m depth to surface) on several occasions during (a) 2000 and (b) 2001 at a fixed station in the Baltic Sea. The open circles in (b) represent the depth-averaged parasite prevalence calculated from discrete depth measurements between July and October 2001

during this study. During the survey period of 2000, the percentage of infected cells was below the detection limit of $0.05 \%$ (i.e. no infected cells observed out of 2000 cells analyzed) on the 5 sampling occasions from April to June. A peak was observed in July, when $2.3 \%$ of cells were found to contain the Amoebophrya sp. trophont, with a gradual decrease to undetectable values (September and late October, Fig. 5a). Similarly, during the sampling period of 2001, infected $D$. norvegica cells were first observed in June at levels of $0.1 \%$, and peaked at $1.8 \%$ in August. The samples taken in September and October 2001 contained detectable amounts of infected cells, at levels of 0.6 and $0.5 \%$, respectively (Fig. 5b). Depth-averaged parasite prevalence calculated from the discrete depth values from July to October 2001 were only slightly higher than the ones obtained from the vertical net tows, showing the same temporal pattern (Fig. 5b).

The parasite prevalence in Dinophysis norvegica was not homogeneous throughout the depth profiles (Fig. 2). Infection close to the surface was usually below $1 \%$. In September, parasite prevalence increased towards the deeper layers, with the value at $20 \mathrm{~m}(4.8 \%)$ being 12 times higher than at the surface $(0.4 \%)$. A similar trend was observed in August and October, although the highest parasite prevalence $(2 \%)$ was detected at $15 \mathrm{~m}$ (close to the thermocline) and decreased at $20 \mathrm{~m}$ (Fig. 2).

The size of the parasite trophont inside Dinophysis norvegica at different depths was measured from samples taken in August and September 2001. On both occasions, the modal size-class shifted towards large sizes as depth increased (Fig. 6). This pattern was more evident in September, with a higher percentage of trophonts found in the intermediate size classes $(25$ to $30 \mu \mathrm{m}$ ) from the surface down to $10 \mathrm{~m}$ depth, changing to larger size classes ( 30 to $35 \mu \mathrm{m}$ and $>35 \mu \mathrm{m}$ ) at $20 \mathrm{~m}$ depth. The smallest trophonts that could be detected with DAPI staining were approximately $12 \mu \mathrm{m}_{\text {; the }}$ largest ones, occupying almost the whole host's intracellular space, were up to $40 \mu \mathrm{m}$.

No correlation was observed between dissolved inorganic nutrient concentration, N:P ratio, or host density and parasite prevalence on Dinophysis norvegica, neither for single-depth measurements nor depth-averaged values (data not shown). Similarly, no correlation was found between water temperature and parasite prevalence on samples from the different depths analyzed from July to October 2001. However, depth-averaged parasite prevalence had a positive correlation with surface water temperatures above $12^{\circ} \mathrm{C}$, while no infection was observed below this temperature (Fig. 7).

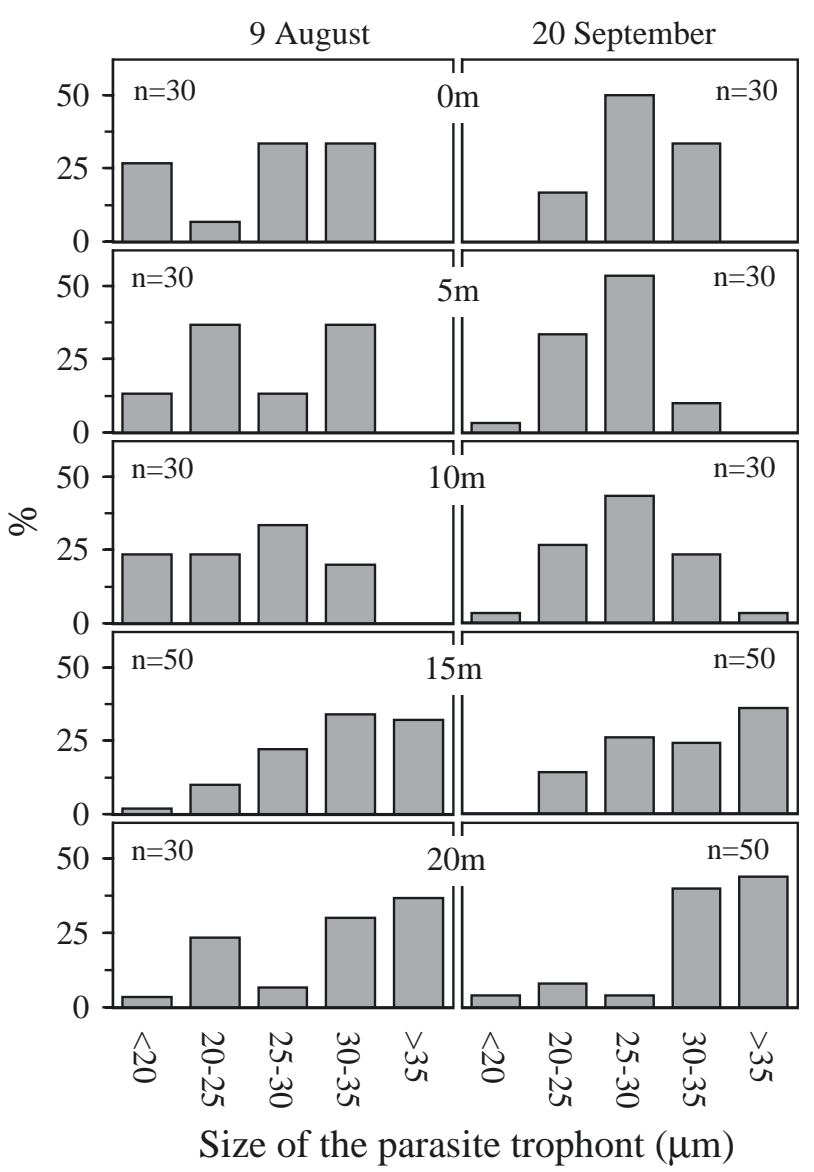

Fig. 6. Frequency distribution of the Amoebophrya sp. trophont size observed inside Dinophysis norvegica through the water column in August and September 2001. Number of trophonts analyzed in each sample (n) is shown 


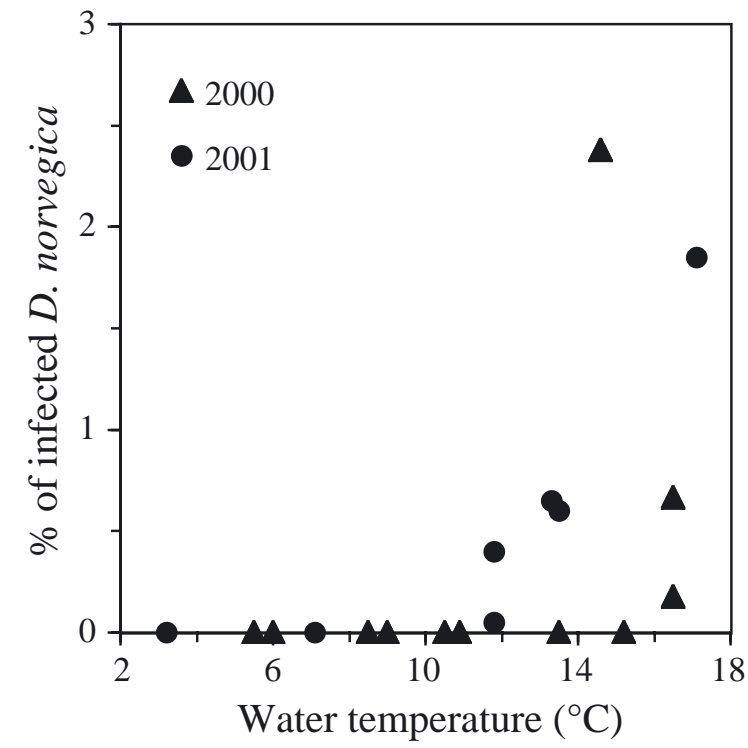

Fig. 7. Depth-averaged infection prevalence of Dinophysis norvegica by Amoebophrya sp. versus surface water temperature for 18 sampling occasions in the Baltic Sea during 2000 and 2001

\section{Parasite emergence from Dinophysis norvegica}

Mature Amoebophrya sp. trophonts were visible inside live cells with bright-field microscopy (Fig. 4a). The green fluorescence characteristic of Amoebophrya sp. parasites was evident under blue light excitation (Fig. 4b), contrasting with the yellow-orange fluorescence of the host (Fig. 4c). Notably, hosts carrying considerably large trophonts were observed to swim, and host flagellar activity could still be seen a few minutes before the parasite emergence. The emergence of Amoebophrya sp. from Dinophysis norvegica was a very active process, typically completed within 2 to $8 \mathrm{~min}$ (Fig. 41 to q). Intense and synchronized flagellar beating of the trophont preceded its emergence from the host. The subsequent evagination of the trophont pushed away the 2 large hypothecal plates of the host, and the parasite, now as a vermiform stage, emerged from the posterior region (Fig. $4 \mathrm{~m}$ to o). The approximately $70 \mu \mathrm{m}$ long vermiform (Fig. 4o to q) contained 100s of flagella, whose synchronized activity caused the whole syncytium to move spirally around its longitudinal axis. Such behavior seemed to facilitate the rupture of the vermiform through the host thecal plates. Once outside, the vermiform swam away rapidly in the same spiral fashion, leaving behind the empty theca of its former host. The individual dinospores broke free of the vermiform within 30 to $40 \mathrm{~min}$. Attack of new hosts by the dinospores was not observed. Deviations from this pattern include unsuccessful emergences from the host characterized by the sudden fading of the parasite's flagellar activity followed by the degeneration of the trophont (within 5 to $10 \mathrm{~min}$ ), and also cases where the vermiform stayed connected for several minutes to the host theca by a mucous filament (Fig. 4q).

\section{DISCUSSION}

The pattern observed during the 2 seasonal monitoring periods in this study shows that the infection of the Dinophysis norvegica population by Amoebophrya sp. is a recurrent phenomenon in the Baltic Sea.

Different techniques have been applied to detect the parasite Amoebophrya sp. inside its hosts. Mature parasite trophonts can be visualized with bright field or epifluorescence microscopy (Fritz \& Nass 1992, Coats \& Bockstahler 1994), although in the latter case the parasite's green autofluorescence fades away soon after fixation. DNA dyes similar to the one we used here have also been previously employed to visualize the parasite and estimate the percentage of infection (Fritz \& Nass 1992, Gisselson et al. 2002). Nevertheless, young stages of the parasite's intracellular phase are difficult to detect, leading to underestimation of the prevalence. A more elaborate technique, Quantitative Protargol Staining, has been extensively used to observe those small stages of the parasite (Coats \& Bockstahler 1994, Coats et al. 1996). However, this technique has also been found to underestimate the small parasite stages when compared to in situ hybridization of fluorescently labelled DNA probes (Gunderson et al. 2001). Therefore, the latter technique seems to be the most accurate tool so far available for this purpose. Preliminary results comparing hybridization assays using a DNA probe designed specifically for the Baltic Sea Amoebophrya sp. rRNA and the DAPIstaining technique on samples collected in August 2001 in the Baltic Sea revealed that DAPI gives, on average, $18 \%$ lower values (P. S. Salomon unpubl.). This is due to the fact that the fluorescently labelled probes allow for the detection of smaller forms of the parasite than the DAPI-staining method.

Amoebophrya sp. prevalence observed during this study was low when compared to values reported for other hosts (Nishitani et al. 1985, Coats et al. 1996, Maranda 2001). Infected Dinophysis norvegica cells were detected on only 8 of the 18 sampling occasions during 2000 and 2001. At specific depths, infection never reached more than $5 \%$ of the host population, and the maximum depth-averaged value was $2.3 \%$. A previous report on the infection of $D$. norvegica by Amoebophrya sp. in the Baltic Sea showed a maximum of $6 \%$ (but no more than $3 \%$ on average) during several time series analyzed during summer months 
(Gisselson et al. 2002). Low infection (2\%) was also reported for a D. norvegica population in Mahone Bay, Nova Scotia, during 4 d monitoring, with no epidemic outbreak preceding the decline of the host population (Fritz \& Nass 1992). The seasonal patterns of $D$. norvegica densities (Fig. 3) and parasite prevalence (Fig. 5) suggest a causal relationship between the decline of $D$. norvegica population and the onset of parasite infection. Yet, epidemic outbreaks of Amoebophrya sp. in other host populations have been shown to develop in the course of few weeks or days (Wakeman \& Nishitani 1982, Coats et al. 1996). Therefore, the possibility that an event of occasionally higher infection was missed due to the time span between sampling occasions cannot be excluded. In addition, the fact that Amoebophrya sp. produces 100s of dinospores per generation, while the host reproduces by binary fission, is a feature that enables a rapid spread of the infection within the host population. However, host-parasite interactions in nature depend on many factors (Combes 2001), and further explanations for the low infection observed in the Baltic Sea include particular hydrological conditions, low host density, interaction with the food web and intrinsic characteristics of this particular host-parasite system. High Amoebophrya sp. prevalence in host populations is usually observed in confined areas associated with high temperatures and host densities above the threshold required for an epidemic outbreak to occur (Coats et al. 1996, Maranda 2001). Our sampling station was at a $65 \mathrm{~m}$ depth area in the open Baltic Sea, and the $D$. norvegica densities observed during this study were relatively low (maximum 1500 cells $\mathrm{l}^{-1}$ ). Similarly, low infection prevalence of Amoebophrya sp. on D. norvegica was previously reported at host concentrations of 4000 cells $1^{-1}$ in the Gotland Deep, several kilometers north of our sampling location (Gisselson et al. 2002). It seems that within this range of host density in the open waters of the Baltic Sea, no suitable conditions are reached to favor frequent events of high infection of $D$. norvegica by Amoebophrya sp. However, this host species has been occasionally observed at densities of $>50000$ cells $1^{-1}$ in the Gotland Deep (Carpenter et al. 1995). If there is a threshold imposed by host density for the initiation of an outbreak, high infection prevalence may be found in periods of such high host density. Additionally, grazing pressure by ciliates on free-swimming Amoebophrya sp. dinospores can strongly suppress the infection process under culture conditions and is also likely to influence infection in nature (Maranda 2001, Johansson \& Coats 2002). Furthermore, low infection levels may be an intrinsic characteristic of this particular host-parasite system. Low infectivity by the parasite and avoidance by the host are possible mechanisms that still await investiga- tion. The fact that some host-parasite systems are more easily maintained in culture than others reflects such particularities. The unsuccessful emergences from the host that we observed on several occasions illustrate quite well the complexity involved in the interaction between host and parasite. The spread of infection through the host population depends on a series of successful events leading to the production of large numbers of new free-living, infective dinospores. Each Amoebophrya sp. trophont that fails to leave its host represents an immediate reduction in the pool of potentially infective forms of the parasite. Additionally, the duration of the emergence process of Amoebophrya sp. observed here was longer than that reported for other hosts-parasite systems (Cachon 1964, Coats \& Bockstahler 1994). Particular structural features of the host (e.g. the thick D. norvegica theca) could be one reason for the apparently difficult emergence. More likely, a combination of the factors presented above is the cause for the low infection of $D$. norvegica by Amoebophrya sp. observed in the Baltic Sea. Taking all these arguments into account, the impact of parasitism is unlikely to be a relevant loss factor for $D$. norvegica populations in the Baltic Sea.

Maybe the most obvious question that rises from the seasonal infection pattern observed for the Baltic Sea Dinophysis norvegica-Amoebophrya sp. system is how does the parasite survive at low densities or absence of D. norvegica? Some hypotheses to explain this pattern include: (1) the existence of one or more alternative hosts; (2) survival of the free-swimming dinospores for long periods outside the host; and (3) dormancy or encystment of the parasite dinospores. The sporadic infection of $D$. acuminata and a peridinoid dinoflagellate observed during this study seems to agree with the first hypothesis. Although not common, under culture conditions, the attack of host dinoflagellates by nonprimary Amoebophrya sp. dinospores has been reported (Coats \& Park 2002). However, molecular identification has shown that morphologically similar Amoebophrya sp. parasites coexisting in the same area are highly diverged organisms (Gunderson et al. 2002). Thus, the parasite inside potential alternative hosts must be genetically examined in order to know whether they are the same species infecting $D$. norvegica or not. Hitherto, the only Amoebophrya sp. characterized by DNA sequencing in the Baltic Sea is the one infecting D. norvegica. Dinospores of Amoebophrya sp. infecting Karlodinium micrum were shown to remain infective for up to $11 \mathrm{~d}$ outside its host (Coats \& Park 2002). However, much longer survival of the free-living dinospores would be necessary to account for time spans of several weeks without detectable infection within the host population. The existence of a resting stage of the parasite seems to be necessary to account 
for the seasonal pattern of infection observed in the Baltic Sea.

The higher percentage of infected hosts and larger sizes of the parasite trophonts observed at deeper layers (Figs. $2 \& 6$ ) are likely to be the result of sedimentation and accumulation of infected cells at the base of the thermocline. Such a phenomenon was previously observed in Chesapeake Bay populations of Gymnodinium sanguineum infected by Amoebophrya sp. (Coats \& Bockstahler 1994). The authors concluded that the sedimentation of infected cells coupled to the host's diel vertical migration caused spatial segregation of hosts and parasites, reducing the chances of infection. Such a mechanism is unlikely to take place in the Baltic Sea Dinophysis norvegica-Amoebophrya sp. system, since the host does not show signs of diel vertical migration in this environment (Carpenter et al. 1995, Gisselson et al. 2002).

Temperature seemed to be an important factor for the infection process of Dinophysis norvegica by Amoebophrya sp. to take place, overcoming the influence of host density and nutrients. This was not surprising since temperature has a direct effect on metabolism and growth rates. Indeed, temperature has been shown to influence the infection process of fungi on the diatom Asterionella formosa by directly affecting the developmental time of the parasite (Van Donk \& Ringelberg 1983). Increased thickness of the cell wall of the host diatoms at low temperatures, which makes it less permeable for fungal parasites, was suggested as a possible indirect effect of temperature (Van Donk 1989).

The percentage of a given host population killed per day by Amoebophrya sp. can be estimated by dividing the parasite prevalence by the duration in days of the parasite's intracellular phase (Coats \& Bockstahler 1994). The intracellular development time of Amoebophrya sp. infecting several host dinoflagellates ranges between 1.4 and $3 \mathrm{~d}$ at $20^{\circ} \mathrm{C}$ (Coats \& Park 2002). Assuming a development time of $2 \mathrm{~d}$ for the Amoebophrya sp. infecting Dinophysis norvegica (corrected for in situ temperature using a $Q_{10}$ of 2 ) shows that only a small fraction of the host population $\left(<0.25 \% \mathrm{~d}^{-1}\right.$ on a yearly average) was lost due to parasitism (Fig. 8). These are low values, even considering that the estimate is likely to be biased when applying the development time of one host-parasite system to another. The impossibility to raise $D$. norvegica in cultures makes the study of its parasite development time difficult. Our attempts to use manipulated, natural D. norvegica populations for this purpose failed due to discontinuity of infection, possibly caused by grazing of the parasite dinospores by ciliates that were present in the samples.

The impact of Amoebophrya sp. parasites on their host populations is variable, being relevant compared

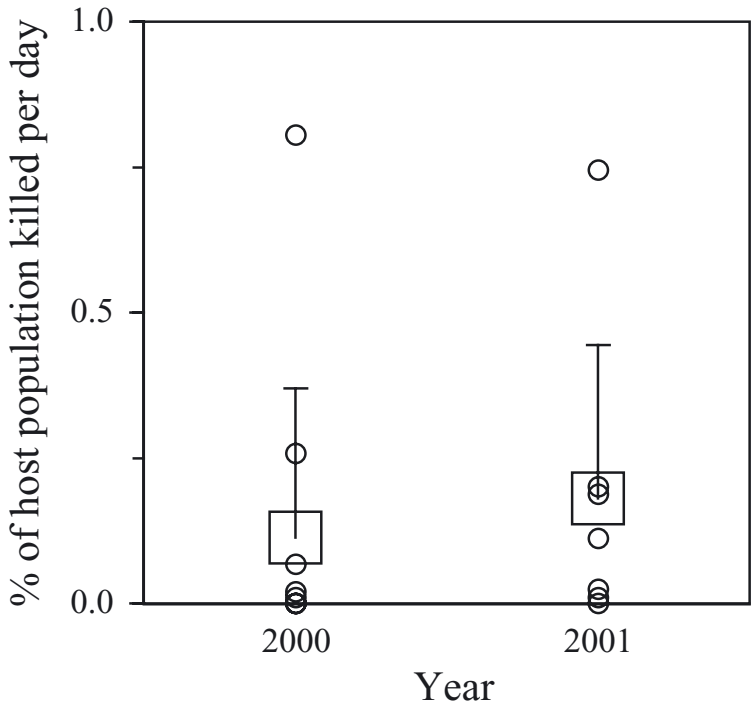

Fig. 8. Estimates of Amoebophrya sp. impact on Baltic Sea Dinophysis norvegica (expressed as \% of the host population killed per day). Values for each occasion (O) (random noise was added to some values to make them visible). Yearly averages $(\square)$. Whiskers $=1 \mathrm{SD}$

to the host's growth rate only under specially favorable circumstances (Nishitani et al. 1985, Coats \& Bockstahler 1994). Based on the percentage of infected hosts estimated in summer months, Gisselson et al. (2002) concluded that loss rates of Dinophysis norvegica due to Amoebophrya sp. infection during their study in the Baltic Sea (Gotland Deep) were irrelevant compared to the observed growth rates of the host during the same period. Our results showed similarly low parasite prevalence during most of the year and indicate that events of high infection prevalence, if they ever occur, are not a common phenomenon for this particular host-parasite system in the Baltic Sea.

Acknowledgements. This work was supported by the European Commission through the BIOHAB project 'Biological control of harmful algal blooms in European coastal waters: role of eutrophication' (contract EVK3-CT99-00015). The BIOHAB project is part of the EC EUROHAB cluster. P.S.S. thanks the Brazilian National Research Council (CNPq) for his $\mathrm{PhD}$ grant. The authors thank C. Esplund-Lindquist and G. Wannhoff for nutrient analysis and sampling assistance, and 3 anonymous reviewers for valuable comments on the manuscript.

\section{LITERATURE CITED}

Cachon J (1964) Contribution à l'étude des péridiniens parasites. Cytologie, cycles évolutifs. Ann Sci Nat Zool 6:1-158

Cachon J, Cachon M (1969) Ultrastructures des Amoebophrydae (Péridiniens Duboscquonida) I. Manifestations des rapports entre l'hôte et le parasite. Protistologica 5: $535-547$ 
Cachon J, Cachon M (1987) Parasitic dinoflagellates. In: Taylor FJR (ed) The biology of dinoflagellates. Blackwell Scientific Publications, Oxford, p 571-610

Carpenter EJ, Janson S, Boje R, Pollehne F, Chang J (1995) The dinoflagellate Dinophysis norvegica: biological and ecological observations in the Baltic Sea. Eur J Phycol 30:1-9

Coats DW (1999) Parasitic life styles of marine dinoflagellates. J Eukaryot Microbiol 46:402-409

Coats DW, Bockstahler KR (1994) Occurrence of the parasitic dinoflagellate Amoebophrya ceratii in Chesapeake Bay populations of Gymnodinium sanguineum. J Eukaryot Microbiol 41:586-593

Coats DW, Park MG (2002) Parasitism of photosynthetic dinoflagellates by three strains of Amoebophrya (Dinophyta): parasite survival, infectivity, generation time, and host specificity. J Phycol 38:520-528

Coats DW, Adam EJ, Gallegos CL, Hedrick S (1996) Parasitism of photosynthetic dinoflagellates in a shallow subestuary of Chesapeake Bay, USA. Aquat Microb Ecol 11: $1-9$

Combes C (2001) Parasitism: the ecology and evolution of intimate interactions. The University of Chicago Press, Chicago

Drebes G (1984) Life cycle and host specificity of marine parasitic dinoflagellates. Helgol Meeresunters 37:603-622

Fritz L, Nass M (1992) Development of the parasitic dinoflagellate Amoebophrya ceratii within host dinoflagellate species. J Phycol 28:312-320

Gisselson LÅ, Carlsson P, Granéli E, Pallon J (2002) Dinophysis blooms in the deep euphotic zone of the Baltic Sea: do they grow in the dark? Harmful Algae 1:401-418

Gunderson JH, Goss SH, Coats DW (2001) FISH probes for the detection of the parasitic dinoflagellate Amoebophrya sp. infecting the dinoflagellate Akashiwo sanguinea in Chesapeake Bay. J Eukaryot Microbiol 48:670-675

Gunderson JH, John SA, Boman C II, Coats DW (2002) Multiple strains of the parasitic dinoflagellate Amoebophrya exist in Chesapeake Bay. J Eukaryot Microbiol 49:469-474

Janson S, Gisselson LÅ, Salomon PS, Granéli E (2000) Evi-

Editorial responsibility: Paul Harrison,

Kowloon, Hong Kong dence for multiple species within the endoparasitic dinoflagellate Amoebophrya ceratii as based on 18S rRNA gene-sequence analysis. Parasitol Res 86:929-933

Johansson M, Coats DW (2002) Ciliate grazing on the parasite Amoebophrya sp. decreases infection of the red-tide dinoflagellate Akashiwo sanguinea. Aquat Microb Ecol 28:69-78

Maranda L (2001) Infection of Prorocentrum minimum (Dinophyceae) by the parasite Amoebophrya sp. (Dinoflagellea). J Phycol 37:245-248

Nishitani L, Erickson G, Chew KK (1985) Role of the parasitic dinoflagellate Amoebophrya ceratii in control of Gonyaulax catenella populations. In: Anderson DM, White AW, Baden DG (eds) Toxic dinoflagellates. Elsevier Science Publishers, New York, p 225-230

Taylor FJR (1968) Parasitism of the toxin-producing dinoflagellate Gonyaulax catenella by the endoparasitic dinoflagellate Amoebophrya ceratii. J Fish Res Board Can 25:2241-2245

Utermöhl H (1958) Zur Vervollkommnung der quantitativen Phytoplankton Methodik. Mitt Int Ver Limnol 9:1-38

Valderama JC (1995) Methods of nutrient analysis. In: Hallegraeff GM, Anderson DM, Cembella AD (eds) Manual of harmful marine microalgae. IOC Manuals and Guides No 33, UNESCO, Paris, p 251-268

Van Donk E (1989) The role of fungal parasites in phytoplankton succession. In: Sommer U (ed) Plankton ecology: succession in plankton communities. Springer Verlag, New York, p 171-194

Van Donk E, Ringelberg J (1983) The effect of fungal parasitism on the succession of diatoms in Lake Maarsseveen I (The Netherlands). Freshw Biol 13:241-251

Wakeman JS, Nishitani L (1982) Growth and decline of Gonyaulax cantenella bloom associated with parasitism. J Shellfish Res 2:122

Yih W, Coats W (2000) Infection of Gymnodinium sanguineum by the dinoflagellate Amoebophrya sp.: effect of nutrient environment on parasite generation time, reproduction, and infectivity. J Eukaryot Microbiol 47: 504-510

Submitted: April 25, 2003; Accepted: July 9, 2003

Proofs received from author(s): September 8, 2003 